\title{
The Radix Entomolaris and Radix Paramolaris: An Endodontic Challenge
}

\author{
${ }^{1}$ Manoj Agarwal, ${ }^{2} \mathrm{HP}$ Trivedi, ${ }^{3}$ Meetu Mathur, ${ }^{4}$ Deepak Goel, ${ }^{5}$ Sankalp Mittal
}

\begin{abstract}
Success of endodontic treatment depends on the proper identification of all the canals, thorough chemomechanical preparation followed by three-dimensional obturation with hermetic seal. Failure of any of these steps may occur due to unusual tooth morphology. Usually mandibular molars have two roots with three canals but in few teeth, the number of roots and canals vary. The variation in the number of roots, if extra root located lingually called radix entomolaris (RE) or located bucally called radix paramolaris (RP). This article presents successful endodontic treatment of two mandibular first molars with extra roots one is with radix entomolaris and other is with radix paramolaris, both of which are rare microstructures.
\end{abstract}

Keywords: Anatomical variations, Endodontic treatment, Mandibular first molars, Radix entomolaris, Radix paramolaris.

How to cite this article: Agarwal M, Trivedi HP, Mathur M, Goel D, Mittal S. The Radix Entomolaris and Radix Paramolaris: An Endodontic Challenge. J Contemp Dent Pract 2014;15(4): 496-499.

\section{Source of support: Nil}

Conflict of interest: None declared

\section{INTRODUCTION}

A thorough knowledge of dental anatomy and an understanding of the potential for variations from the normal are required to achieve success in endodontics. Incomplete instrumentation and cleaning of the root canal space and faulty obturation are the main reasons for failure of endodontic treatment. Root canals are often left untreated because the operator fails to recognize their presence, especially in teeth exhibiting anatomic irregularities or accessory or aberrant root canals. ${ }^{1,2}$

\footnotetext{
${ }^{1,3-5}$ Assistant Professor, ${ }^{2}$ Professor and Head

1,2,4 Department of Conservative Dentistry and Endodontics Government Dental College, Jaipur, Rajasthan, India

${ }^{3}$ Department of Conservative Dentistry and Endodontics Rajasthan Dental College, Jaipur, Rajasthan, India

${ }^{5}$ Department of Oral and Maxillofacial Surgery, Government Dental College, Jaipur, Rajasthan, India
}

Corresponding Author: Manoj Agarwal, Assistant Professor Department of Conservative Dentistry and Endodontics Government Dental College, Jaipur, Rajasthan, India, Phone: 919414214658, e-mail: drmanojgdc@gmail.com
Anatomical variations are an acknowledged characteristic of mandibular permanent molars. Permanent mandibular first molars usually have 2 roots placed mesially and distally and 3 root canals, but variations in the number of roots and in canal morphology are not uncommon. The presence of a third root in the permanent first molar is the major variant in this group. ${ }^{2,3}$

This additional third root, first mentioned in the literature by Carabelli (1844), is called the radix entomolaris (RE), located distolingually in the mandibular molars, mainly first molars. An additional root at the mesiobuccal side is called the radix paramolaris (RP). ${ }^{4}$ The permanent mandibular first molar is the earliest permanent posterior tooth to erupt, responsible for development of occlusion and important physiologic functions like chewing. Commonly, it is the most frequently in need of endodontic treatment. Thus, it is of utmost importance that the clinician be familiar with variations in the root and root canal anatomy of the mandibular first molar. ${ }^{5,6}$

\section{Morphology of RE}

Classification given by Carlsen and Alexanderson describes the four different types of RE according to the location of the cervical part of the RE. ${ }^{7-9}$

Type A - Distally located cervical part with two normal distal root components.

Type B - Same as type A but only one normal distal component.

Type $\mathrm{C}$ - Mesially located cervical part.

Type AC - Central location between mesial and distal root components. ${ }^{10}$

De Moor et al classified RE-based on the curvature in buccolingual orientation into three types.

Type I - Refers to a straight root/root canal.

Type II - Refers to an initially curved entrance which continues as a straight root/root canal.

Type III - Refers to an initial curve in the coronal third of the root canal and a second buccally oriented curve starting from middle to apical third. ${ }^{11,12}$

Carlsen and Alexanderson describes two different types of RP. ${ }^{\text {? }}$

Type A - Refers to an RP in which the cervical part is located on the mesial root complex. 
Type B - Refers to an RP in which the cervical part is located centrally, between the mesial and distal root complexes.

\section{Incidence of Mandibular Molar with Three Roots}

The presence of a separate RE in the first mandibular molar is associated with certain ethnic groups. In African populations a maximum frequency of $3 \%$ is found, while in Eurasian and Indian populations the frequency is less than $5 \%$. In populations with Mongoloid traits (such as the Chinese, Eskimo and American Indians) reports have noted that the RE occurs with a frequency that ranges from 5\% to more than $30 \%$. Because of its high frequency in these populations, the RE is considered to be a normal morphological variant (eumorphic root morphology). In Caucasians the RE is not very common and, with a maximum frequency of 3.4 to $4.2 \%$, is considered to be unusual or dysmorphic root morphology. ${ }^{13-15}$

An RE can be found on the first, second and third mandibular molar, occurring least frequently on the second molar. ${ }^{16}$ Some studies report a bilateral occurrence of the RE from 50 to $67 \%{ }^{17}$

Radix Paramolaris (RP): This macrostructure is very rare and occurs less frequently than the RE. ${ }^{18} \mathrm{RP}$ is commonly observed in 1.5 to $3 \%$ of African population whereas RP is less frequent in Indian population. Its frequency of existence is around $2 \%$. The prevalence of RP, as observed by Visser was found to be $0 \%$ for the first mandibular molar, $0.5 \%$ for the second and $2 \%$ for the third molar. ${ }^{16}$

\section{Etiology}

The etiology behind the formation of third root in a mandibular molar is still unclear. In dysmorphic, supernumerary roots, its formation could be related to external factors during odontogenesis, or to penetrance of an atavistic gene or polygenetic system (atavism is the reappearance of a trait after several generations of absence). In eumorphic roots, racial genetic factors influence the more profound expression of a particular gene that results in the more pronounced phenotypic manifestation. ${ }^{15,19}$

\section{CASE REPORTS}

\section{Case 1 (Radix Entomolaris)}

A 28-year-old female patient reported with complains of pain in the right lower back tooth region. She gave a history of intermittent pain for the past 1 month, which had increased in intensity since 2 days. On examination, the right mandibular first molar was carious with pulpal involvement and tender on percussion. Thermal and electrical pulp testing of the tooth elicited a negative response. The diagnostic radiograph showed widening of the periodontal ligament space and an additional root between the mesial and distal roots. Two radiographs with different horizontal angulations were made which confirmed that the additional root was located distolingual to the mesial root (Fig. 1A). Medical history was noncontributory. A diagnosis of a nonvital right mandibular first molar with apical periodontitis was made and endodontic treatment was planned.

The tooth was anesthetized and then isolated under rubber dam. The access cavity was prepared using an endo access bur. One distal and two mesial canal orifices were located using an endodontic explorer. Upon close inspection a dark line was observed between the distal canal orifice and the distolingual corner of the pulp chamber floor. At this corner overlying dentin was removed and a second distal canal orifice was detected. The canal lengths were determined using radiograph and an apex locator (Fig. 1B). Cleaning and shaping was performed using protaper rotary instrument in crown down technique. Irrigation between each instrument was done using $2.5 \%$ sodium hypochlorite and $17 \%$ EDTA. After the master cone selection canals were obturated with gutta-percha and AH plus sealer. Post endodontic restoration was placed (Figs 1C and D).

\section{Case 2 (Radix Paramolaris)}

A 52-year-old female patient reported to the department with the complaint of pain in the lower left back tooth region. Patient gave a history of pain since 2 weeks. Diagnostic radiograph revealed carious lesion close to the pulp with a faint outline of an additional root overlapping the mesial root of left mandibular first molar (Fig. 2A). Clinical, radiographic examination and pulp testing of left mandibular first molar revealed that the tooth was asymptomatic. A diagnosis of a nonvital left mandibular first molar with apical periodontitis was made and endodontic treatment was planned.

The tooth was anesthetized and isolated under rubber dam. The access cavity was prepared. On inspection of the pulp chamber floor centrally placed two canal orifices (one mesial and one distal) were detected initially. A small hemorrhagic spot was noted buccally between the distal and the mesial orifices on the pulp chamber floor. Bubbles were noted when a drop of sodium hypochlorite was placed on the hemorrhagic spot (Champagne bubble test) and the opening was confirmed as a buccal canal orifice. Working length determined using radiographs and an apex locater, cleaning and shaping was done using rotary protaper files (Fig. 2B). Canals were irrigated with $2.5 \%$ sodium hypochlorite and $17 \%$ EDTA. After selecting the master cones, canals were obturated with gutta-percha and $\mathrm{AH}$ plus sealer. The access cavity was restored with silver amalgam (Figs 2C and D). 

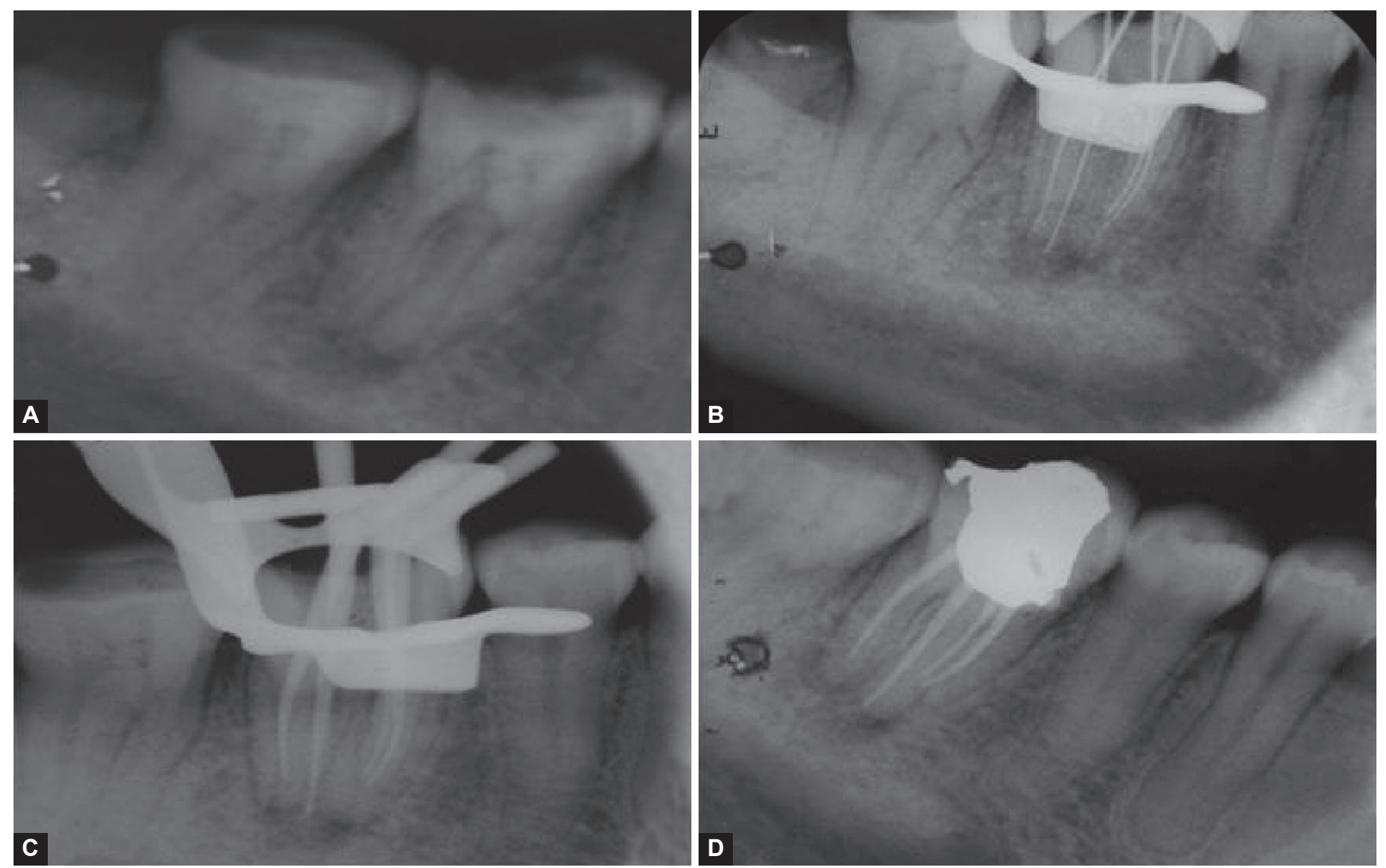

Figs 1A to D: (A) Diagnostic radiograph, (B) Working length radiograph, (C) Master cone radiograph, (D) Postobturation radiograph (case 1)

\section{DISCUSSION}

The presence of an RE or an RP has clinical implications in endodontic treatment. An accurate diagnosis of these supernumerary roots can avoid complications or a 'missed canal' during root canal treatment. A thorough inspection of the preoperative radiograph and interpretation of particular marks or characteristics, such as an unclear view or outline of the distal root contour or the root canal, can indicate the presence of a 'hidden' RE. To reveal the RE, a second radiograph should be taken from a more mesial or distal angle $\left(20^{\circ}\right)$. This way an accurate diagnosis can be made in the majority of cases. Apart from a radiographical diagnosis, clinical inspection of the tooth crown and analysis of the cervical morphology of the roots by means of periodontal probing can facilitate identification of an additional root. An extra cusp (tuberculum paramolare) or more prominent occlusal distal or distolingual lobe, in combination with a cervical prominence or convexity, can indicate the presence of an additional root. If an RE or RP is diagnosed before endodontic treatment, one knows what to expect or where to look once the pulp chamber has been opened.

The location of the orifice of the root canal of an RE has implications for the opening cavity. The orifice of the RE is located disto to mesiolingually from the main canal or canals in the distal root. An extension of the triangular opening cavity to the (disto) lingual results in a more rectangular or trapezoidal outline form. If the RE canal entrance is not clearly visible after removal of the pulp chamber roof, a more thorough inspection of the pulp chamber floor and wall, especially in the distolingual region, is necessary. Visual aids such as a loupe, intraoral camera or dental microscope can, in this respect, be useful. A dark line on the pulp chamber floor can indicate the precise location of the RE canal orifice. The distal and lingual pulp chamber wall can be explored with an angled probe to reveal overlying dentin or pulp roof remnants masking the root canal entrance. ${ }^{15}$

\section{CONCLUSION}

Unlike in other races, RE and RP in mandibular first molar is not a frequent finding in the Indian population. However, Dental clinician should be aware of the occurrence of RE and RP as an anatomical variant. The detection of RE and RP and its thorough cleaning, shaping and obturation would contribute significantly toward the success of primary endodontic treatment. Further, mandibular first molars have lower success rate following root canal treatment due to factors like missed canal, etc, and awareness about extra root helps in the diagnosis and to better the overall prognosis for endodontic retreatment. For the above reasons, molars also have high rate of extraction and early identification of extra distolingual root will minimize complications related to exodontia like root breakage. This case report also highlights 


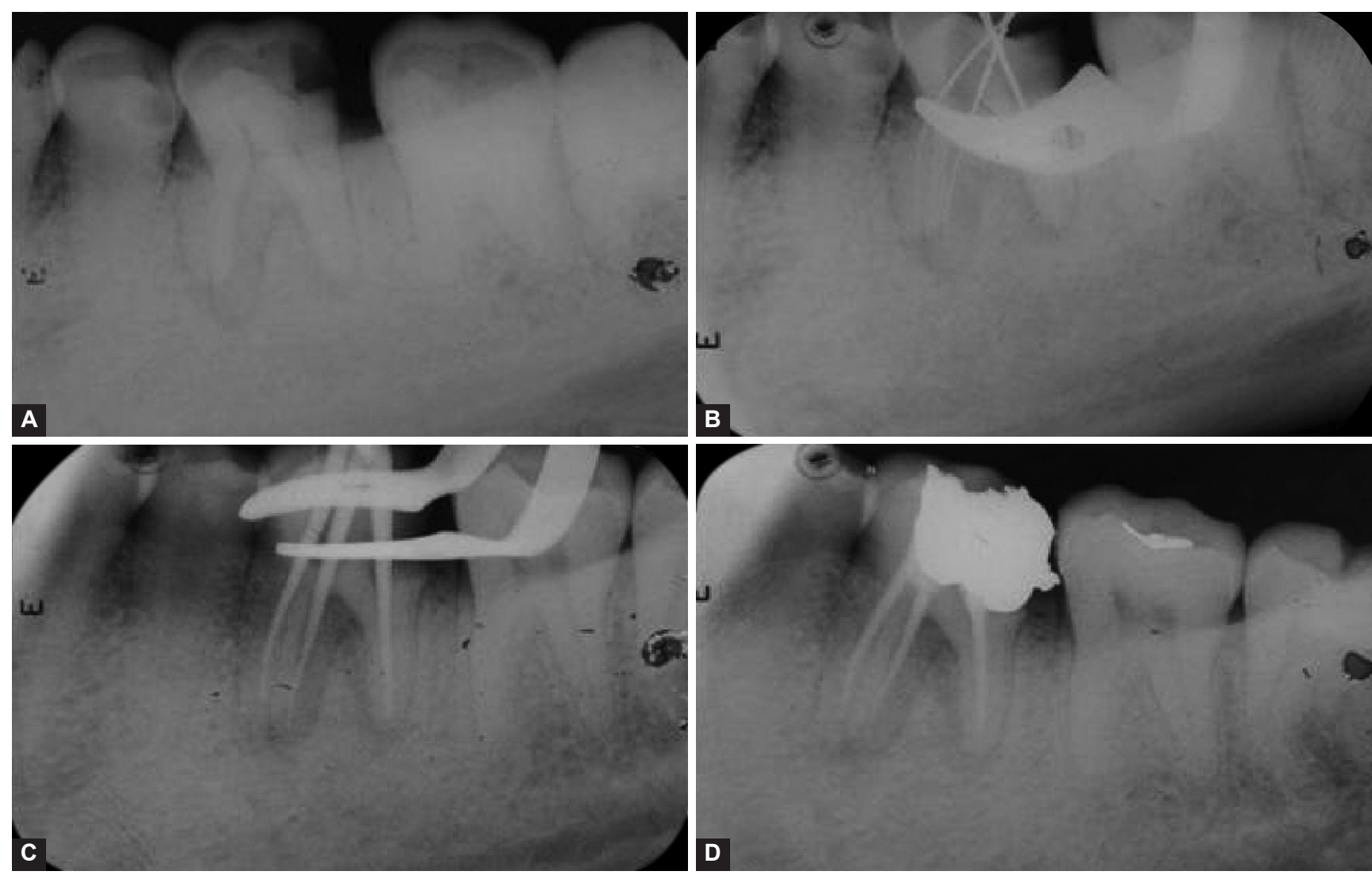

Figs 2A to D: (A) Diagnostic radiograph, (B) Working length radiograph, (C) Master cone radiograph, (D) Postobturation radiograph (case 2)

the role of radiographs alone in the early identification and endodontic management of RE and RP.

\section{REFERENCES}

1. Prabhu NT, Munshi AK. Additional distal root in permanent mandibular first molars: report of a case. Quintessence International 1995;26(8):567-569.

2. Segura-Egea JJ, Jimenez-Pinzon A, Rios-Santos JV. Endodontic therapy in a 3-rooted mandibular first molar: Importance of a thorough radiographic examination. J Can Dent Assoc 2002; 68(9):541-544.

3. Tu MG, Huang HL, Hsue SS, Hsu JT, Chen SY, Jou MJ, et al. Detection of permanent three-rooted mandibular first molar by cone-beam computed tomography imaging in Taiwanese individuals. J Endod 2009;35:503-507.

4. Bolk L. The importance of endodontic in maxillary and mandibular molar canals. J Can Dent Assoc 1994;60:527-532.

5. Barker BCW, Parson KC, Mills PR, Williams GL. Anatomy of root canals. III. Permanent mandibular molars. Aust Dent J 1974; 19:403-413.

6. Vertucci F. Root canal anatomy of the human permanent teeth. Oral Surg Oral Med Oral Pathol 1984;58:589-599.

7. Carlsen O, Alexanderson V. Radix paramolaris in permanent mandibular molars: identification and morphology. Eur J Oral Sci 1991;99:189-195.

8. Grossman LI. In: Endodontic Practice. 11th ed. California: Lea and Febiger 1987;145-178.
9. Ingle JI, Bakland LK, Endodontic cavity preparation. In: Endodontics. 5th ed. 2002:405-510.

10. Ribeiro FC, Consolaro A. Importancia clinica y antropologica de la raiz distolingual en los molars inferiores permamentes. Endodont 1997;15:72-78 (English Abstr).

11. Bolla N, Kavuri SR, Sriram SK. Radix entomolaris: report of 3 cases. J Orofac Sci 2010;2(1):43-45.

12. De Moor RJ, Deroose CA, Calberson FL. The radix entomolaris in mandibular first molars: an endodontic challenge. Int Endod J 2004;37:789-799.

13. Tratman EK. Three-rooted lower molars in man and their racial distribution. Br Dent J 1938;64:264-274.

14. Yew SC, Chan K. A retrospective study of endodontically treated mandibular first molars in a Chinese population. J Endod 1993; 19:471-473.

15. Calberson FL, De Moor RJ, Deroose CA. The radix entomolaris and paramolaris: clinical approach in endodontics. J Endod 2007; 33(1):58-63.

16. Visser JB. Beitrag zur Kenntnis der menschlichen Zahnwurzelformen. Hilversum: Rotting 1948. p. 49-72.

17. Steelman R. Incidence of an accessory distal root on mandibular first permanent molars in Hispanic children. J Dent Child 1986; 53:122-123.

18. Bolk L. Welcher Gebibreihe gehören die Molaren an? Z Morphol Anthropol 1914;17:83-116.

19. Reichart PA, Metah D. Three-rooted permanent mandibular first molars in the Thai. Community Dent Oral Epidemiol 1981;9: 191-192. 